\title{
Influence of Age on Compensatory Renal Growth in Rats
}

\author{
GIANNI CELSI, BIRGIR JAKOBSSON, AND ANITA APERIA \\ Department of Developmental Physiology and Pediatrics, St. Göran's Children's Hospital and Huddinge \\ Hospital, Stockholm, Sweden [B.J., A.A.] and Department of Pediatrics, University of Milano, Italy [G.C.]
}

\begin{abstract}
Rats were nephrectomized (nx) or shamoperated (s) at the age of 5 days (young) or 55 days (adult). $\mathrm{Nx}$ and $\mathrm{s}$ rats from the same litters were studied at various times 5-75 days after surgery with determination of kidney weight and of renal cortical DNA and protein content. In some protocols protein and DNA content were determined in a more homogenous population of proximal tubular cells. In $s$ rats body weight, kidney weight, renal cortical DNA content, and protein/DNA ratio increased until at least 80 days of age. Body growth was the same in $n x$ and $s$ rats. In young nx rats the remnant kidney was significantly enlarged 5 days after surgery. The difference in kidney size between $n x$ and $s$ rats increased continuously at least until the age of 80 days. The remnant kidney was $125 \pm 9 \%$ enlarged 3 wk after $n x$ and $175 \pm 18 \%$ enlarged 8 wk after nx. Five days after nx there was no increase in cortical DNA content but a significant increase in protein/DNA ratio. From 2 wk after nx on, the DNA content was significantly higher in $n x$ than in $s$ rats but the protein/ DNA ratio was the same in $n x$ and $s$ rats. In adult $n x$ rats, the remnant kidney was enlarged to the same extent 3 and 8 wk after surgery $(130 \pm 7$ and $132 \pm 8 \%$, respectively). The increase in kidney weight 8 wk after nx was significantly smaller in adult than in young rats. The cortical DNA content and protein/DNA ratio were both moderately but significantly increased in adult rats 8 wk after $n x$. In conclusion this study has established age-dependent differences regarding the degree, the nature and the duration of compensatory renal growth. These differences can probably be attributed to the high mitotic capacity that is unique in the young kidney. (Pediatr Res 20: 347-350, 1986)
\end{abstract}

\section{Abbreviation}

CRG, compensatory renal growth

Several studies both in animals (1-5) and in humans (6-9) suggest that CRG is influenced by age. Thus it has been reported that 1) the degree of CRG is greater $(10,11), 2)$ the hyperplasia is proportionally greater $(1-3,12), 3)$ and the $C R G$ continues for a longer period in the young than in the adult subject $(10)$. However, these conclusions are disputed. Some authors find that CRG does not change with age (13). The studies which report that CRG in the young is due more to hyperplasia than to hypertrophy are not conclusive.

Received September 12, 1985; accepted December 16, 1985.

Address correspondence to Anita Aperia, Department of Developmental Physiology, The Karolinska Institute, St. Göran's Children's Hospital, Box 12500, S-11281 Stockholm, Sweden.

Supported by grants from the Swedish Medical Research Council (B84-19X03644-13A).
Several methodological problems are involved in studies of the age dependence of CRG, since the rapid normal growth of the kidney and the body must be taken into account. To be conclusive, studies on the effect of age on CRG should be performed in large series of animals, where nephrectomized animals are compared to sham-operated littermates at various times after nephrectomy. In the present study we have used this approach and have determined the degree and duration of CRG and the proportion of hyperplasia and hypertrophy in the remnant kidney of rats nephrectomized in infancy and followed until adulthood. The degree and duration of CRG in rats nephrectomized in infancy has then been compared to the degree and duration of CRG in rats nephrectomized in adulthood.

\section{MATERIALS AND METHODS}

Male Sprague-Dawley rats ranging in age from 5 to 110 days were used. The rat pups were separated from their mothers at the age of 21 days. The rats were fed a standard diet containing $21 \%$ protein. Water was provided ad libitum.

Procedure. Animals in the same litter were randomly assigned for unilateral nephrectomy or sham-operation. The nephrectomy was performed under light ether anesthesia. The left kidney was exposed through a flank incision and gently dissected from the adrenal gland. The same operation was performed on shamoperated animals, except that the kidney was not touched. Infant rats were nephrectomized or sham-operated at the age of 5 days. They were then returned to their mothers. Adult rats were nephrectomized or sham-operated at the age of 55 days. The postoperative mortality was less than $5 \%$ in both infant and adult rats.

At the time of the study the animals were weighed, anesthetized with Inactin $(80 \mathrm{mg} / \mathrm{kg}$ intraperitoneal, Promonta, West Germany) and the right kidney was removed and weighed. Immediately thereafter the cortex was dissected from the medulla under stereomicroscopy at $2 \times$ magnification. We had no difficulty in distinguishing the border between the cortex and the medulla in rats aged 10 days or older. The cortex was weighed and immediately frozen at $-70^{\circ} \mathrm{C}$. The dissection and weighing procedures lasted for less than $2 \mathrm{~min}$. During this period no significant evaporation occurred.

In one group of rats nephrectomized at the age of 5 days and sacrificed at the age of 60 days, only the outer $150 \mu \mathrm{m}$ of the cortex was used for analysis of DNA and protein content. Immediately after the kidney was removed, the outer cortical slice was sectioned with a modified Stadie-Riggs microtome, weighed, and frozen.

Analysis of tissue DNA and protein content. DNA was measured in the homogenate of the renal cortex by a colorimetric reaction with diphenylamine (14). In most of the assays 100-200 $\mathrm{mg}$ of cortex was homogenized in $2 \mathrm{ml}$ of $20 \mathrm{mM}$ phosphate buffer with a pH of 7.2 with a Teflon-glass homogenizer (four strokes at $1000 \mathrm{rpm})$. The homogenate was then ultracentrifuged at $100,000 \times g$ for $50 \mathrm{~min}$. 
After ultracentrifugation the pellet was suspended in $2.5 \mathrm{ml}$ of cold $5 \%$ trichloroacetic acid for $15 \mathrm{~min}$. After centrifugation for $15 \mathrm{~min}$ at $3300 \times g$ the supernatant was removed, the pellet was suspended in $3 \mathrm{ml}$ of $1.5 \mathrm{M} \mathrm{HClO}_{4}$ and DNA was hydrolyzed in water bath at $70^{\circ} \mathrm{C}$ during a period of $15 \mathrm{~min}$. After $20 \mathrm{~h}$ at room temperature in a dark room, the absorption was read on a Beckman spectrophotometer at 595 and $700 \mu \mathrm{m}$. In each assay we checked the linearity of the reaction, adding $1 \mathrm{ml}$ of diphenylamine solution ( $4 \%$ diphenylamine, $0.01 \%$ paraldehyde in $\mathrm{HAC})$ to three different dilutions of hydrolyzed DNA (1:100, $1: 150$, and 1:200). Calf thymus DNA from Sigma Co., St. Louis, MO, was used as standard.

In pilot studies we found that 1-2 mg DNA, diluted according to the assay we used, gave complete linearity. We needed $100-$ $500 \mathrm{mg}$ renal cortex to obtain 1-2 mg DNA. In most protocols we obtained a sufficient amount of tissue for DNA analysis from one rat. In 5-day-old rats we had to pool cortical tissue from two rats to obtain $100 \mathrm{mg}$ of material. For analysis of the DNA content in the outer $150 \mu \mathrm{m}$ cortical slices we had to pool tissue from four to five rats. The protein concentration of the homogenate was measured by the Lowry micromethod (15).

Calculations and statistical analysis. Data are given as mean \pm 1 SD. Six animals were used in each of the groups studied. The statistical analysis was performed with the unpaired Student's $t$ test. A $p$ value less than 0.05 was considered significant. For comparisons of nephrectomized and sham-operated rats, the individual value in nephrectomized rats has sometimes been calculated as percentage of the mean value in sham-operated littermates.

\section{RESULTS}

Normal kidney growth. In a pilot study we found no statistical differences between control nonoperated rats and sham-operated rats with respect to any of the parameters studied. Body weight and kidney weight increased continuously from the neonatal period until the age of 80 days. The cortical DNA content increased significantly from day 5 to day 10 and continued to increase significantly from day 15 to 20 , from day 20 to 40 and from day 40 to 80 (Fig. 1). The increment in cortical DNA content was most rapid between day 10 and $20(111 \mu \mathrm{g} /$ day $)$ and declined with increasing age.

The protein/DNA ratio increased significantly from day 5 to 20 , from day 20 to 40 , and from day 40 to 80 (Fig. 1). The daily increase in the protein/DNA ratio was more rapid between day 20 and 40 than between day 5 and 20 .

$C R G$ in young rats. The body weight was not at any age significantly different in nephrectomized and sham-operated rats (Fig. 2). The kidney weight was significantly greater in nephrectomized than in sham-operated rats in all age groups, but the

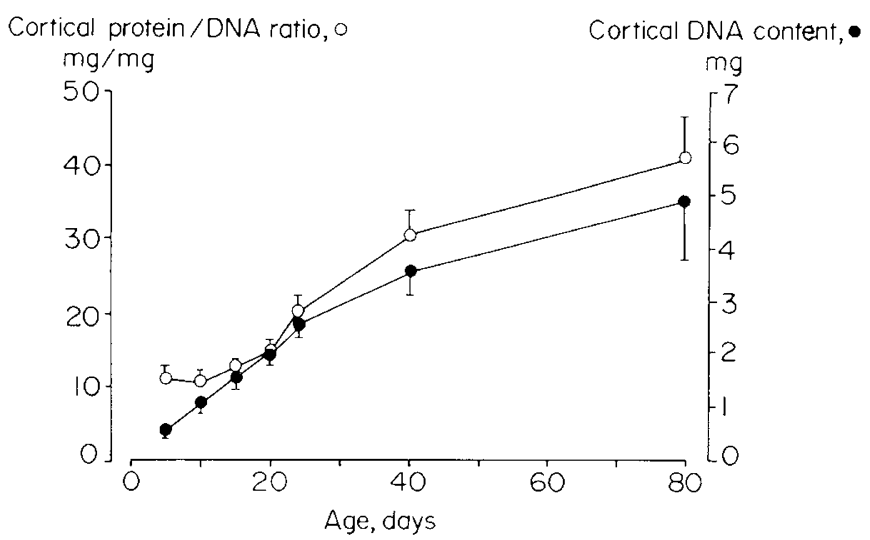

Fig. 1. Cortical DNA content (filled circles) and protein/DNA ratio unfilled circles) during normal growth. Values are mean $\pm 1 \mathrm{SD}, n=6$ $\mathrm{n}$ each group.
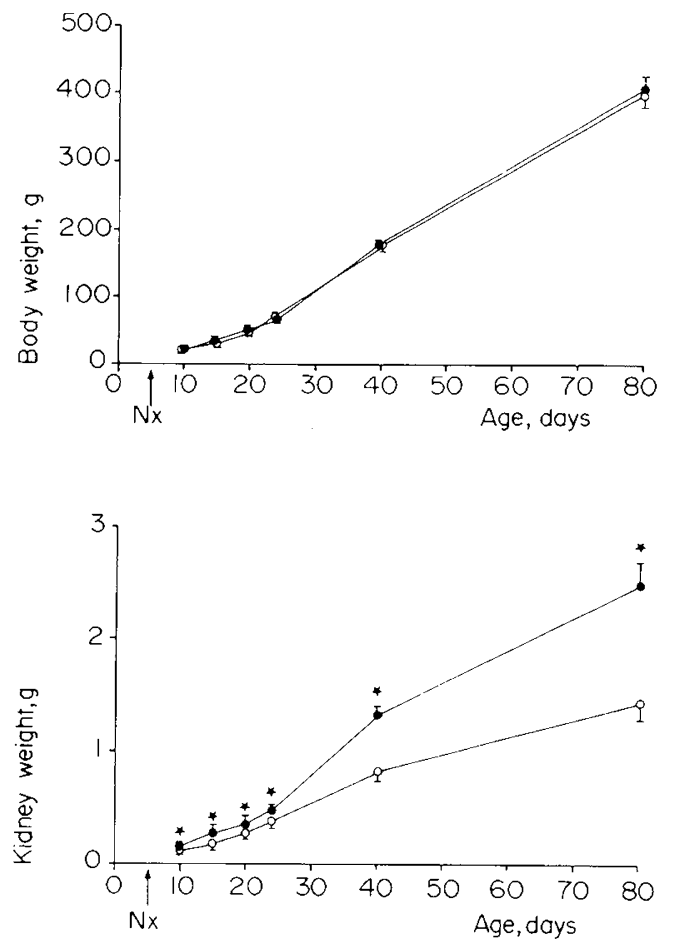

Fig. 2. Body weight (upper panel) and kidney weight (lower panel) in unilaterally nephrectomized (filled circles) and sham-operated (unfilled circles) rats. The time of surgery is indicated by the arrows. Stars indicate statistically significant differences between the nephrectomized and sham-operated rats of corresponding age. Values are mean $\pm 1 \mathrm{SD}, n=$ 6 in each group.
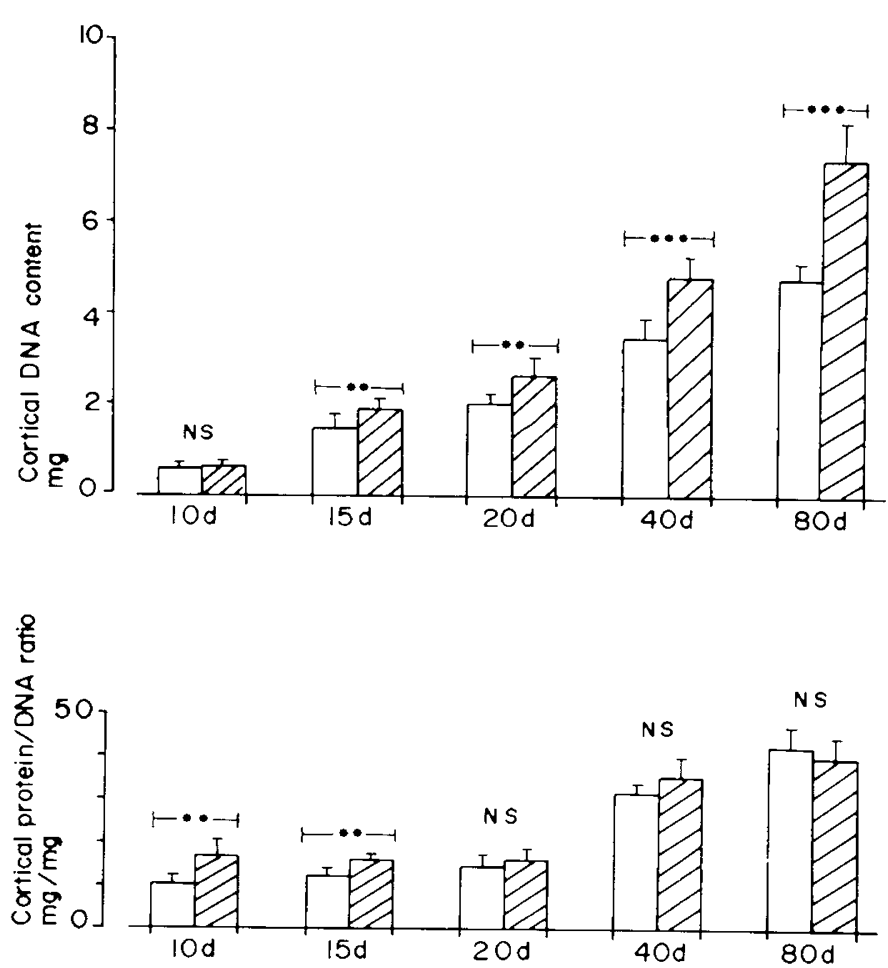

Fig. 3. Cortical DNA content and protein/DNA ratio in rats nephrectomized (hatched bars) and sham-operated (unfilled bars) at 5 days of life and studied at different ages. Asterisks indicate statistically significant differences between the nephrectomized and sham-operated rats of corresponding age ( $\mathrm{NS}=$ not significant, $\mathrm{XX}=p<0.01, \mathrm{XXX}=p<$ $0.001)$. Values are mean $\pm 1 \mathrm{SD}, n=6$ in each group. 
difference between the groups increased gradually from 10 to 80 days of life (Fig. 2).

In Figure 3 we compare the cortical DNA content and protein/ DNA ratio in nephrectomized and sham-operated young rats. The cortical DNA content was the same in nephrectomized and sham-operated rats 5 days after surgery, i.e. when the rats were 10 days old. When the rats were 15 days old, the remnant kidney had a significantly higher DNA content than one kidney in sham-operated rats. The difference between the two groups increased steadily up until 80 days of age and was significant at all ages above 10 days. At the age of 80 days the DNA content in the remnant kidney was $176 \pm 17 \%$ increased.

Unilateral nephrectomy at 5 days of age was followed by an immediate increase in cortical protein/DNA ratio in the remnant kidney. A the ages of 10 and 15 days the cortical protein/DNA ratio was significantly higher in nephrectomized than in shamoperated rats. From the age of 20 to the age of 80 days the cortical protein/DNA ratio was the same in nephrectomized and sham-operated rats.

The protein/DNA ratio was also determined in the outer renal cortex in rats operated at 5 days of age and sacrificed $8 \mathrm{wk}$ later. The outer cortical protein/DNA ratio was the same in nephrectomized and sham-operated rats (Table 1).

Comparisons between $C R G$ in young and adult rats. In Figure 4 we compare the degree of $C R G$ in young and adult rats at 3 and $8 \mathrm{wk}$ after nephrectomy. In adult rats the remnant kidney was $130 \pm 7 \%$ enlarged $3 \mathrm{wk}$ after nephrectomy and $132 \pm 8 \%$ enlarged $8 \mathrm{wk}$ after nephrectomy. These values are not significantly different. In contrast, in the young rats, there was a pronounced increase in the difference in kidney size between nephrectomized and sham-operated rats 3 and $8 \mathrm{wk}$ after operation. At 3 wk after nephrectomy, the remnant kidney was 125

Table 1. Protein/DNA ratio in tissue from the outer $150 \mu \mathrm{m}$ of the cortex in 60-day-old nephrectomized and control rats

\begin{tabular}{|c|c|}
\hline & $\begin{array}{c}\text { Protein/DNA } \\
(\mathrm{mg} / \mathrm{mg})\end{array}$ \\
\hline $\begin{array}{l}\text { Nephrectomized, } n^{*}=4 \\
\text { Control, } n^{*}=3\end{array}$ & $\begin{array}{c}59.5 \pm 8.2 \\
53.4 \pm 1.6 \\
p>0.2\end{array}$ \\
\hline
\end{tabular}

* Number of analysis. Tissue from four to five littermates were used for each analysis.

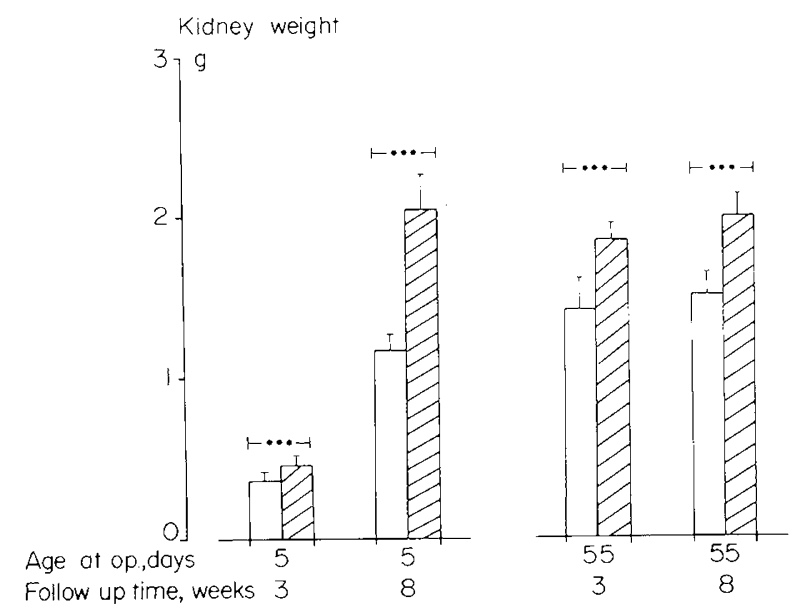

Fig. 4. Kidney weight in rats nephrectomized (hatched bars) and sham-operated (unfilled hars) at the age of 5 days (left panel) or 55 days (right panel). The rats were studied 3 or 8 wk postoperatively. Asterisks indicate statistically significant differences between the nephrectomized and sham-operated rats of corresponding age $(\mathrm{XXX}=p<0.001)$. Values are mean $\pm 1 \mathrm{SD}, n=6$ in each group.

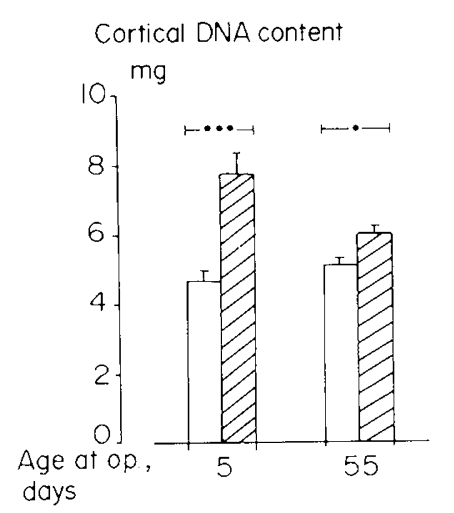

Cortical protein /DNA ratio $\mathrm{mg} / \mathrm{mg}$

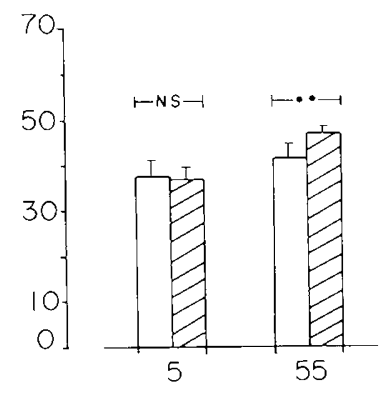

Fig. 5. Cortical DNA content (left panel) and cortical protein/DNA ratio (right panel) in rats nephrectomized (hatched bars) and shamoperated (unfilled bars) at the age of 5 or 55 days. The rats were studied 8 wk postoperatively. Asterisks indicate statistically significant differences between the nephrectomized and sham-operated rats of corresponding age. (NS = not significant, $\mathrm{X}=P<0.05, \mathrm{XX}=p<0.01 . \mathrm{XXX}=p<$ $0.001)$. Values are mean $\pm 1 \mathrm{SD}, n=6$ per each group.

$\pm 9 \%$ enlarged and at 8 wk after nephrectomy the remnant kidney was $175 \pm 18 \%$ enlarged. The enlargement of the remnant kidney at $8 \mathrm{wk}$ was significantly more pronounced in young than in adult rats.

In Figure 5 we compare the change in cortical DNA content and protein/DNA ratio in the remnant kidney in young and adult rats. The studies were performed $8 \mathrm{wk}$ after nephrectomy. In the adult rat, the DNA content and protein/DNA ratio were increased to an equal extent $(116 \pm 6$ and $114 \pm 4 \%$, respectively), while in the young rat there was a large and highly significant increase in DNA content but no increase in the protein/DNA ratio.

\section{DISCUSSION}

Methodology. Cell size and cell number were estimated by a procedure which is based on the constancy of the amount of DNA per nucleus in most rat organs, regardless of age (16). The total amount of cortical DNA can therefore be considered as an approximate index of cell number, and the protein/DNA ratio gives a mean figure for the amount of cytoplasmic material associated with a single nucleus. The protein/DNA ratio may therefore be used as an index of the average cell size. However, there are many different types of renal cells and considerable differences in the size of these cells. The finding that the average renal cortical protein/DNA ratio was not increased in young nephrectomized rats studied more than 2 wk after surgery, therefore does not necessarily indicate the absence of cellular hypertrophy. Theoretically, a constant renal protein/DNA ratio would also occur if there were an overall increase in cell size but at the same time a redistribution in cell population with a relative increase in the number of small cells, such as loop of Henle cells. In order to reduce the degree of cellular heterogeneity, we therefore chose to study the cortex only. In the renal cortex, proximal tubular cells are predominant (17). CRG is mainly due to the growth of the proximal tubules (18). To confirm that the constancy of the cortical protein/DNA ratio which we observed in nephrectomized and sham-operated young rats 2 to $10 \mathrm{wk}$ after nephrectomy indicates a lack of increase in proximal tubular cell size, we also determined the protein/DNA ratio in the outer 150 $\mu \mathrm{m}$ layer of the renal cortex. We have previously shown that this tissue consists of more than $85 \%$ of proximal tubular cells (19). Since the protein/DNA ratio in this rather homogeneous population of proximal tubular cells was the same in nephrectomized and sham-operated rats, we conclude that there is no permanent 
hypertrophy of proximal tubular cells in rats nephrectomized in infancy.

Normal renal growth. We found, in accordance with several previous studies $(1,3)$, that normal kidney growth takes place through a dual process of cell multiplication and cell enlargement. After publication of the studies by Winick and Noble (20) it was accepted for almost a decade that the kidney first grows by cell multiplication and later by an increase in cell size and that, in the rat kidney, cell multiplication is completed at the age of about 40 days. This concept was challenged by Sands et al. (21) who in 1979 reported that in the rat kidney cell multiplication continued until the age of at least 80-90 days. Our findings corroborate those of Sands et al. (21). The discrepancy between the more recent observations and the findings of Winick and Noble (20) can probably be explained by methodological differences, and mainly by the difference in diet. Between 40 and 80 days of age the rats studied by Sands et al. (21) and by us grew twice as rapid as the rats studied by Winick and Noble (20). In accordance with Sands et al. (21) we therefore suggest that kidney cell multiplication does not cease at a certain age but continues so long as the body is rapidly growing.

$C R G$. We found that CRG initiated in infancy is based on hyperplasia alone, when rats reach adult age. Since it is now well established that unilateral nephrectomy in infancy does not result in the formation of new nephrons (5), the increase in cortical cell number in the remnant kidney implies that the number of cells in each nephron is increased.

The observation that CRG initiated in infancy is based solely on cell multiplication is new. Dicker and Shirley (3) reported that, following nephrectomy in infancy, there is an increase in renal cell size but that the cellular enlargement is less pronounced than following nephrectomy in adulthood. However, they presented no absolute values for body weight and kidney size, DNA content, and protein/DNA ratio following nephrectomy. Karp et al. (1) reported that nephrectomy performed in 40-day-old rats resulted in kidney cell multiplication but not in kidney cell enlargement. However, they also found that if nephrectomy was performed in 4-day-old rats CRG was achieved more by enlargement than by multiplication of the kidney cells. It is difficult to compare the two studies since their follow-up times were shorter than ours. Moreover, they used a more heterogeneous cell population (whole kidney homogenate) than we did and they reported no body weights.

In our study we observed a temporary increase in cell size after nephrectomy. The increase in cell size observed in the remnant kidney in the nephrectomized rats preceded by a few days the rapid increase in cell size that occurs during normal growth. It is therefore possible that the transitory increase in cell size observed in the nephrectomized rats reflects a precocious maturation induced by the growth stimulus.

We found great differences between CRG initiated in infancy and CRG initiated in adulthood. The relative increase in kidney weight was much less pronounced in adult than in young animals. This observation corroborates previous findings in young and adult rats (1-4, 10,12), dogs (23), and guinea-pigs (22), but does not accord with a study in growing mice (13). It is possible that the controversial findings are due to differences in species. However, the study of CRG in mice used an allometric approach, in which the data from infant and young adult animals were grouped together. It cannot be excluded that this approach may have obscured moderate differences between the groups. We also found that in adult animals CRG resulted to an equal extent from hyperplasia and hypertrophy. The hyperplasia was much less pronounced in nephrectomized adult rats than in nephrectomized young rats. This implies that the mitotic capacity is markedly reduced after renal cells have reached terminal differentiation.
We also demonstrated that CRG continues for a longer period if it starts in infancy. In accordance with previous studies we found that in adult rats CRG is almost completed within 3 wk. In the young rats, the differences in kidney weight and DNA content between the remnant kidney in the nephrectomized rats and the control kidney in the sham-operated rats continued to increase untill at least $8-10 \mathrm{wk}$ after surgery. The time course of CRG initiated in infancy has not been defined previously, but Galla et al. (4), who compared the effects of nephrectomy in weanling and adult rats, found that $\mathrm{CRG}$ continued for a longer period in the weanling rats. Clinical observations, based on radiological studies (8) of the growth of the remnant kidney after nephrectomy, have also suggested that $\mathrm{CRG}$ initiated in childhood has a long duration.

Acknowledgments. The authors acknowledge the expert technical assistance of Ms. Ann-Christine Eklöf and Ms. MarieLouise Syrén.

\section{REFERENCES}

I. Karp R, Brasel JA, Winick M 1971 Compensatory kidney growth after uninephrectomy in adult and infant rats. Am J Dis Child 121:186-188

2. Dicker SE. Shirley DG 1971 Mechanism of compensatory renal hypertrophy. J Physiol 219:507-523

3. Dicker SE, Shirley DG 1973 Compensatory renal growth after unilateral nephrectomy in the newborn rat. J Physiol 228:193-202

4. Galla JH, Klein-Robbenhaar T. Hayslett JP 1974 Influence of age on the compensatory response in growth and function to unilateral nephrectomy. Yale J Biol Med 47:218-226

5. Larsson L, Aperia A. Wilton P 1980 Effect of normal development on compensatory renal growth. Kidney Int 18:29-35

6. Ogden DA 1967 Donor and recipient function 2 to 4 years after renal homotransplantation. A paired study of 28 cases. Ann Intern Med 67:9981006

7. Boner G, Shelp W, Newton M, Rieselbach RE 1973 Factors influencing the increase in glomerular filtration rate in the remaining kidney of transplant donors. Am J Med 55:169-174

8. Aperia A, Broberger O. Wikstad I, Wilton P 1977 Renal growth and function in patients nephrectomized in childhood. Acta Pediatr Scand 66:185-192

9. Claesson I. Jacobsson B, Jodal U, Winberg J 1981 Compensatory kidney growth in children with urinary tract infection and unilateral renal scarring: An epidemiologic study. Kidney Int 20:759-764

10. Kaufman JM, Hardy R, Hayslett JP 1975 Age-dependent characteristics of compensatory renal growth. Kidney Int $8: 21-26$

11. Hayslett JP 1983 Effect of age on compensatory renal growth. Kidney Int 23:599-602

12. Soukupová M, Hnevkovský P, Najbrt J 1975 Effect of age on kidney hyperplasia in the rat after unilateral nephrectomy. Adv Exp Med Biol 53:297305

13. Hutson JM, Holt AB, Egami K. Niall M. Fowler R and Cheek B 1981 Compensatory renal growth in the mouse. I. Allometric approach to the effect of age. Pediatr Res 15:1370-1374

14. Richards GM 1974 Modifications of the diphenylamine reaction giving increased sensitivity and simplicity in the estimation of DNA. Anal Biochem 57:369-376

15. Lowry OH, Rosebrough NJ, Farr HL, Randall RJ 1951 Protein measurement with the Folin-phenol reagent. J Biol Chem 193:265-275

16. Enesco M, Leblond CP 1962 Increase in cell number as a factor in the growth of the organs and tissues of the young male rat. J Embryol Exp Morphol 10:530-562

17. McFarlane D 1941 Experimental phosphate nephritis in the rat. J Pathol Bacteriol 52:17-24

18. Hayslett JP, Kashgarian M, Epstein FH 1968 Functional correlates of compensatory renal hypertrophy. J Clin Invest 74:774-782

19. Aperia A. Haldosén L-A, Larsson L, Gustafsson J-A 1985 Ontogeny of triamcinolone-acetonide binding sites in outer cortical tissue from rat kidneys. Am J Physiol 249:F891-897

20. Winick M, Noble A 1965 Quantitative changes in DNA, RNA and protein during prenatal and postnatal growth in the rat. Dev Biol 12:451-466

21. Sands J, Dobbing J, Gratrix CA 1979 Cell number and cell size: Organ growth and development and the control of catch-up growth in rats. Lancet 2:503505

22. Shirley DG 1976 Developmental and compensatory renal growth in the guinea pig. Biol Neonate 30:169-180

23. Aschimberg LC, Koskimies O, Bernstein J, Nash M. Edelman Jr CM, Spitzer A 1978 The influence of age on the response to renal parenchymal loss. Yale J Biol Med 51:341-345 